\title{
MARXISMO E REVISIONISMO 1
}

\section{MARXISMO Y REVISIONISMO}

\section{MARXISM AND REVISIONISM}

DOI: http://dx.doi.org/10.9771/gmed.v12i2.39012

Vladimir Ilitch Lenin ${ }^{2}$

Um conhecido adágio diz que se os axiomas geométricos chocassem com os interesses dos homens, certamente se tentaria refutá-los. As teorias das ciências naturais, que se opunham aos velhos preconceitos da teologia provocaram e continuam a provocar até hoje a mais furiosa luta. Não é de estranhar, portanto, que a doutrina de Marx, que serve diretamente para educar e organizar a classe de vanguarda da sociedade moderna, que indica as tarefas desta classe e demonstra a substituição inevitável em virtude do desenvolvimento econômico - do atual regime por uma nova ordem de coisas, não é de estanhar que esta doutrina tenha tido de conquistar pela luta cada passo no caminho da vida.

Inútil falar da ciência e da filosofia burguesas, ensinadas escolasticamente pelos professores oficiais para embrutecer as novas gerações das classes possuidoras e "amestrá-las" contra os inimigos de fora e de dentro. Esta ciência não quer nem ouvir falar de marxismo, declarando-o refutado e destruído; tanto os jovens homens de ciências, que fazem carreira refutando o socialismo, como os velhos decrépitos, que guardiães dos legados de toda a espécie de "sistemas" caducos, se lançam sobre Marx com o mesmo zelo. Os avanços do marxismo, a difusão e a afirmação de suas ideias entre a classe operária, tornam inevitavelmente mais frequentes e mais agudos esses ataques burgueses contra o marxismo, que sai mais fortalecido, mais temperado e mais ativo após cada uma de suas "destruições" por obra da ciência oficial.

Mas o marxismo não consolidou de forma alguma a sua posição de maneira imediata, mesmo entre as doutrinas vinculadas à luta da classe operária e difundidas principalmente entre o proletariado. Durante o primeiro meio século da sua existência (desde a década de 40 do século XIX), o marxismo lutou contra as teorias que lhes eram radicalmente hostis. Na primeira metade da década de 40, Marx e Engels ajustaram contas com os jovens hegelianos radicais, que se situavam no ponto de vista do idealismo filosófico. Em fins dessa década passa ao primeiro plano, no campo das doutrinas econômicas, a 
luta contra o proudhonismo ${ }^{3}$. Esta luta termina na década de 50: crítica dos partidos e das doutrinas que se tinham manifestado no turbulento ano de 1848 . Na década de 60 , a luta desloca-se do plano da teoria geral para um domínio mais próximo do movimento operário propriamente dito: expulsão do bakuninismo da Internacional. No início da década de 70, destaca-se na Alemanha, por algum tempo, o proudhonista Mühlberger; em fins da década, o positivista Dühring. Mas a influência de ambos sobre o proletariado já é muito insignificante. O marxismo triunfa já, incondicionalmente, sobre todas as outras ideologias do movimento operário.

Por volta da década de 90 do século passado, esse triunfo estava, nas suas linhas gerais, consumado. Até nos países latinos, onde se haviam mantido por mais tempo as tradições do proudhonismo, os partidos operários elaboraram, de fato, os seus programas e sua táctica em bases marxistas. Ao reavivar-se - sob a forma de congressos internacionais periódicos - a organização internacional do movimento operário, esta coloca-se imediatamente, e quase sem luta, em todas as questões essenciais, no terreno do marxismo. Mas quando o marxismo suplantou todas as doutrinas mais ou menos completas que se opunham, as tendências que se expressavam através destas doutrinas começaram a procurar outros caminhos. Modificaram-se as formas e os motivos da luta, mas a luta continuou. E o segundo meio século de existência do marxismo (década de 90 do século passado) começou com a luta de uma corrente hostil ao marxismo no seio do marxismo.

Esta corrente deve seu nome ao ex-marxista ortodoxo Bernstein ${ }^{4}$, que é quem fez mais barulho e quem deu a expressão mais completa às emendas feitas a Marx, à revisão de Marx, ao revisionismo. Mesmo na Rússia, onde o socialismo não marxista, logicamente - em virtude do atraso econômico do país e da preponderância da população camponesa oprimida pelas sobrevivências da servidão -, se manteve por mais tempo, mesmo na Rússia esse socialismo se converte claramente, diante dos nossos próprios olhos, em revisionismo. Tanto na questão agrária (programa de municipalização de toda a terra) como nas questões gerais programáticas e tácticas, os nossos social-populistas substituem cada vez mais por "emendas" a Marx os restos agonizantes e caducos do velho sistema, que era coerente a seu modo e radicalmente hostil ao marxismo.

O socialismo pré-marxista foi derrotado. Já não continua a luta em seu próprio terreno, mas sim no terreno geral do marxismo, como revisionismo. Vejamos, pois, qual é o conteúdo ideológico do revisionismo.

No domínio da filosofia, o revisionismo caminhava a reboque da "ciência" acadêmica burguesa. Os professores "voltavam a Kant", e o revisionismo arrastava-se atrás dos neokantianos"5; os professores repetiam, pela milésima vez, as vulgaridades dos padres contra o materialismo filosófico, e os revisionistas, sorrindo condescendentemente, resmungavam (repetindo palavra por palavra o último Handbuch [Manual]) que o materialismo havia sido "refutado" há muito tempo. Os professores tratavam Hegel como um "cão morto" e, pregando eles próprios, o idealismo, mas um idealismo mil vezes mais mesquinho e banal que o hegeliano, encolhiam desdenhosamente os ombros diante da dialética, e os revisionistas mergulhavam atrás deles no pântano do aviltamento filosófico da ciência, substituindo a 
"sutil" (e revolucionária) dialética pela "simples" (e tranquila) "evolução"; os professores ganhavam os seus ordenados do Estado acomodando os seus sistemas, tanto os idealistas como os "críticos", à "filosofia" medieval dominante (isto é, à teologia), e os revisionistas aproximavam-se deles, esforçando-se por fazer da religião “assunto privado”, não em relação ao Estado moderno, mas em relação ao partido da classe de vanguarda.

Não é preciso dizer que significação real de classe tinham semelhantes “emendas” a Marx; a coisa é clara por si mesma. Assinalaremos apenas que Plekhanov foi o único marxista dentro da socialdemocracia internacional que criticou, do ponto de vista do materialismo dialético consequente, aquelas incríveis banalidades acumuladas pelos revisionistas. É tanto mais necessário sublinhar isto decididamente quanto se fazem nos nossos dias tentativas profundamente errôneas para fazer passar o velho e reacionário lixo filosófico sob o disfarce da crítica ao oportunismo tático de Plekhanov ${ }^{6}$.

Passando à economia política, temos de assinalar, antes de mais nada, que neste campo as "emendas" dos revisionistas eram muitíssimo mais variadas e circunstanciadas; esforçaram-se por sugestionar o público com "novos dados sobre o desenvolvimento econômico". Diziam que no domínio da economia rural não se operam de forma alguma a concentração e suplantação da pequena produção e que no comércio e na indústria a concentração se processa com extrema lentidão. Diziam que, hoje, as crises se tornaram mais raras e mais fracas e que era provável que os cartéis e os trustes dessem ao capital a possibilidade de eliminar por completo as crises. Diziam que a "teoria da bancarrota", para a qual marcha o capitalismo, é inconsistente por causa da tendência para as contradições de classe se suavizarem e atenuarem. Diziam, finalmente, que não seria mau corrigir também a teoria do valor de Marx de acordo com Böhm-Bawerk.

A luta contra os revisionistas nestas questões serviu para um fecundo reavivamento do pensamento teórico do socialismo internacional, tal como ocorrera, vinte anos antes, com a polêmica de Engels com Dühring. Os argumentos dos revisionistas foram analisados com fatos e números na mão. Demonstrou-se que os revisionistas embelezavam sistematicamente a pequena produção atual. A superioridade técnica e comercial da grande produção sobre a pequena, tanto na indústria como na agricultura, é um fato confirmado por dados irrefutáveis. Mas a produção mercantil está imensamente menos desenvolvida na agricultura e os especialistas de estatística e os economistas atuais não sabem, em geral, destacar os ramos (por vezes mesmo as operações) especiais da agricultura que demonstram como ela é integrada progressivamente, no intercâmbio da economia mundial. A pequena produção mantém-se sobre as ruínas da economia natural, graças à infinita piora da alimentação, à fome crônica, ao prolongamento do dia de trabalho, à baixa da qualidade do gado e do tratamento deste; resumindo, com os mesmos meios pelos quais também a produção artesanal se mantivera contra a manufatura capitalista. Cada passo em frente da ciência e da técnica mina, inevitável e inexoravelmente os alicerces da pequena produção na sociedade capitalista. E a tarefa da economia socialista é investigar este processo sob todas as suas formas, não raro complexas e intrincadas, e demonstrar ao pequeno produtor a impossibilidade de se manter sob o capitalismo, a situação desesperada das explorações camponesas no regime capitalista e a 
necessidade de que o camponês aceite o ponto de vista do proletariado. Em relação ao problema que tratamos, os revisionistas cometeram, no aspecto científico, o pecado de generalizar de modo superficial de alguns factos unilateralmente selecionados, desligados da sua conexão com o conjunto do regime capitalista, e, no aspecto político, cometeram o pecado de, voluntária ou involuntariamente, chamar ou impelir inevitavelmente o camponês para o ponto de vista do proprietário (isto é, o ponto de vista da burguesia), em vez de o impelir para o ponto de vista do proletário revolucionário.

$\mathrm{O}$ revisionismo saiu-se ainda pior quanto à teoria das crises e à teoria da bancarrota. Somente durante um espaço de tempo muito curto, e unicamente pessoas muito míopes, podiam pensar em modificar as bases da doutrina de Marx sob a influência de uns poucos anos de ascenso e prosperidade industrial. Não tardou que a realidade se encarregasse de demonstrar aos revisionistas que as crises não tinham desaparecido: após a prosperidade veio a crise. Mudaram as formas, a sucessão, o quadro das diferentes crises, mas elas continuam a ser parte integrante, inevitável, do regime capitalista. Os cartéis e os trustes, unificando a produção, reforçaram ao mesmo tempo, à vista de todos, a anarquia da produção, a insegurança econômica do proletariado e a opressão do capital, agravando dessa forma em grau nunca visto as contradições de classe. Que o capitalismo marcha para a bancarrota - tanto no sentido das crises políticas e econômicas isoladas como no sentido da completa derrocada de todo o regime capitalista demonstraram-no de modo muito palpável e em vasta escala os modernos e gigantescos trustes. A recente crise financeira na América, o espantoso crescimento do desemprego em toda a Europa, sem falar da próxima crise industrial, que muitos sintomas anunciam, tudo isso fez com que as recentes "teorias" dos revisionistas tenham sido esquecidas por todos, e mesmo, ao que parece, por muitos deles próprios. O que não se deve esquecer são os ensinamentos que esta instabilidade dos intelectuais deu à classe operária.

Quanto à teoria do valor, basta dizer que, à parte alusões e suspiros muito vagos, à maneira de Böhm-Bawerk, os revisionistas não trouxeram absolutamente nada de novo a esse respeito, nem deixaram, portanto, qualquer marca no desenvolvimento do pensamento científico.

No campo da política, o revisionismo tentou rever o que realmente constitui a base do marxismo, ou seja, a teoria da luta de classes. A liberdade política, a democracia, o sufrágio universal, destroem a base da luta de classes - diziam-nos os revisionistas - e desmentem o velho princípio do Manifesto Comunista de que os operários não têm pátria. Uma vez que na democracia impera a "vontade da maioria", não devemos ver no Estado, segundo eles, o órgão da dominação de classe, nem negar-nos a entrar em alianças com a burguesia progressista, social-reformista, contra os reacionários.

É indiscutível que estas objeções dos revisionistas se reduziam a um sistema bastante coerente de concepções, a saber: as sobejamente conhecidas concepções burguesas liberais. Os liberais disseram sempre que o parlamentarismo burguês suprime as classes e as diferenças de classe, visto que todos os cidadãos sem excepção têm direito de voto e de intervir nos assuntos do Estado. Toda a história da Europa na segunda metade do século XIX e toda a história da revolução russa, em princípios do século XX, demonstram à evidência como são absurdas tais concepções. Com as liberdades do capitalismo "democrático", as diferenças econômicas, longe de se atenuarem, acentuam-se e agravam-se. O 
parlamentarismo não elimina, antes põe a nu, a essência das repúblicas burguesas mais democráticas como órgãos de opressão de classe. Ajudando a esclarecer e educar massas de população incomparavelmente mais extensas do que as que antes participavam de modo ativo nos acontecimentos políticos, o parlamentarismo prepara assim, não a supressão das crises e das revoluções políticas, mas a maior agudização da guerra civil durante essas revoluções. Os acontecimentos de Paris, na Primavera de 1871, e os da Rússia, no Inverno de 1905, mostraram, com excepcional clareza, como esta agudização se produz inevitavelmente. A burguesia francesa, para esmagar o movimento proletário, não vacilou nem um segundo em pactuar com o inimigo de toda a nação, com as tropas estrangeiras que tinham arruinado a sua pátria. Quem não compreender a inevitável dialética interna do parlamentarismo e da democracia burguesa, que conduz a solucionar a disputa pela violência de massas de modo ainda mais brutal do que anteriormente, jamais saberá desenvolver, na base desse parlamentarismo, uma propaganda e uma agitação consequentes do ponto de vista dos princípios, que preparam verdadeiramente as massas operárias para participarem vitoriosamente em tais "disputas". A experiência das alianças, dos acordos, dos blocos com o liberalismo social-reformista no Ocidente e com o reformismo liberal (democratas-constitucionalistas ${ }^{7}$ na revolução russa, demonstrou, de maneira convincente, que esses acordos não fazem senão embotar a consciência das massas, não reforçando mas debilitando o significado real da sua luta, unindo os lutadores aos elementos menos capazes de lutar, aos elementos mais vacilantes e traidores. O "millerandismo" 8 francês - a maior experiência de aplicação da tática política revisionista numa vasta escala, realmente nacional - deu-nos uma apreciação prática do revisionismo que o proletariado do mundo inteiro jamais esquecerá.

O complemento natural das tendências econômicas e políticas do revisionismo era a sua atitude em relação ao objetivo final do movimento socialista. "O objetivo final não é nada, o movimento é tudo" - esta frase proverbial de Bernstein exprime a essência do revisionismo melhor do que muitas longas dissertações. A política revisionista consiste em determinar o seu comportamento em função das circunstâncias, em adaptar-se aos acontecimentos do dia, às viragens dos pequenos fatos políticos, em esquecer os interesses fundamentais do proletariado e os traços essenciais de todo o regime capitalista, de toda a evolução do capitalismo, em sacrificar estes interesses fundamentais em favor das vantagens reais ou supostas do momento. E da própria essência desta política se deduz, com toda a evidência, que pode tomar formas infinitamente variadas e que cada problema um pouco "novo", cada viragem um pouco inesperada e imprevista dos acontecimentos - embora tal viragem só altere a linha fundamental do desenvolvimento em proporções mínimas e pelo prazo mais curto - dará sempre, inevitavelmente, origem a esta ou àquela variedade de revisionismo.

O caráter inevitável do revisionismo é determinado pelas suas raízes de classe na sociedade atual. O revisionismo é um fenômeno internacional. Para nenhum socialista um pouco informado e consciente pode existir a menor dúvida de que a relação entre os ortodoxos e os bernsteinianos na Alemanha, entre os guesdistas e os jauressistas (agora, em particular os broussistas ${ }^{9}$ ) em França, entre a Federação SocialDemocrata $^{10}$ e o Partido Trabalhista Independente, em Inglaterra ${ }^{11}$, entre De Brouckère e Vandervelde ${ }^{12}$, 
na Bélgica, os integralistas e os reformistas ${ }^{13}$, em Itália, os bolchevistas e os mencheviques na Rússia, é, por toda a parte essencialmente a mesma, não obstante a gigantesca diversidade das condições nacionais e dos fatores históricos na situação atual de todos esses países. A "divisão" no seio do socialismo internacional contemporâneo estabelece-se hoje, nos diversos países do mundo, essencialmente, numa mesma linha, o que mostra um formidável passo em frente que se deu em comparação com o que ocorria há trinta ou quarenta anos, quando lutavam nos diversos países tendências heterogêneas dentro de um movimento socialista internacional único. E esse "revisionismo de esquerda" que toma corpo hoje nos países latinos, com o nome de "sindicalismo revolucionário"14, adapta-se também ao marxismo "emendando-o": Labriola em Itália e Lagardelle em França apelam a cada passo do Marx mal compreendido para o Marx bem compreendido.

Não nos podemos deter aqui no exame do conteúdo ideológico deste revisionismo, que está longe de estar tão desenvolvido como o revisionismo oportunista, e que não se internacionalizou, não travou nem uma única batalha prática de importância com o partido socialista de qualquer país. Por isso nos limitaremos a esse "revisionismo de direita", que esboçamos mais acima.

Em que se baseia a sua inevitabilidade na sociedade capitalista? Por que é mais profundo que as diferenças decorrentes das particularidades nacionais e dos graus de desenvolvimento do capitalismo? Porque em qualquer país capitalista existem sempre, ao lado do proletariado, extensas camadas de pequena burguesia, de pequenos proprietários. O capitalismo nasceu e continua a nascer, constantemente, da pequena produção. O capitalismo cria de novo, infalivelmente, toda uma série de "camadas médias" (apêndice das fábricas, trabalho a domicílio, pequenas oficinas disseminadas por todo o país em virtude das exigências da grande indústria, por exemplo, da indústria de bicicletas e automóveis, etc.). Estes novos pequenos produtores vêem-se por sua vez lançados, também inevitavelmente, nas fileiras do proletariado. É perfeitamente natural que a mentalidade pequeno-burguesa irrompa repetidamente nas fileiras dos grandes partidos operários. É perfeitamente natural que isso suceda, e assim sucederá sempre, chegando às próprias peripécias da revolução proletária, pois seria um profundo erro pensar que é necessário que a maioria da população se proletarize "por completo" para que essa revolução seja realizável. O que hoje vivemos com frequência num plano puramente ideológico, isto é, as disputas em torno das emendas teóricas a Marx; o que hoje só se manifesta na prática a propósito de certos problemas parciais, isolados, tê-lo-á que viver inevitavelmente a classe operária, em proporções incomparavelmente maiores, quando a revolução proletária agudizar todos os problemas em litígio e concentrar todas as divergências nos pontos de importância mais imediata para a determinação da conduta das massas, obrigando a que se separarem, no fragor da luta, os inimigos dos amigos e a que se rejeitem os maus aliados, para assestar golpes decisivos no inimigo.

A luta ideológica do marxismo revolucionário contra o revisionismo, no final do século XIX, não é mais que o prelúdio dos grandes combates revolucionários do proletariado, que, apesar de todas as vacilações e debilidades dos elementos pequeno-burgueses, avança para o triunfo completo da sua causa. 


\section{Notas}

1 Publicado originalmente na brochura Karl Marx (1808-1883), de 1908. Fonte: V.I. Lénine, Obras Escolhidas em três tomos, Edições Avante!, 1977, t.1, p.40-46. Disponível em https://www.marxists.org/portugues/lenin/1908/04/16.htm.

2 Fundador, dirigente do Partido Bolchevique e principal liderança da Revolução Russa até a sua morte em 1924.

3 [Nota das Edições Avante!] Doutrina de Proudhon: corrente anticientífica, hostil ao marxismo, do socialismo pequenoburguês. Criticando a grande propriedade capitalista a partir de posições pequeno-burguesas, Proudhon sonhava com perpetuar a pequena propriedade privada, propunha que fossem organizados os bancos "do povo" e de "troca", que, segundo ele, permitiriam aos operários obter meios de produção próprios, tornar-se artesões e garantir a venda "justa" dos seus produtos. Proudhon não compreendia o papel histórico do proletariado, negava a luta de classes, a revolução proletária e a ditadura do proletariado. Partindo de posições anarquistas, negava também a necessidade do Estado.

4 [Nota das Edições Avante!] Trata-se do bernsteinianismo, corrente oportunista hostil ao marxismo na social-democracia internacional, que surgiu no final do século XIX na Alemanha e deve o seu nome a E. Bernstein, o mais declarado porta-voz do revisionismo. Bernstein, após a morte de F. Engels, empreendeu a revisão da doutrina revolucionária de Marx no espírito do liberalismo burguês, procurando transformar o partido social-democrata num partido pequeno-burguês de reformas sociais. Na Rússia eram partidários do bernsteinianismo os "marxistas legais", os "economistas". os bundistas e os mencheviques.

5 [Nota das Edições Avante!] Neokantianos: representantes de uma corrente reaccionária na filosofia burguesa que surgiu nos meados do século XIX na Alemanha. Os neokantianos repetiam as teses mais reaccionárias e idealistas da filosofia de Kant e rejeitavam os elementos do materialismo que nela havia. Sob a palavra de ordem "voltar a Kant", os neokantianos conduziam a luta contra o materialismo dialéctico e histórico. Lénine apresentou uma crítica de todos os aspectos da filosofia neokantiana no livro Materialismo e Empiriocriticismo (1909).

6 [Nota do autor] Veja-se o livro Ensaios sobre a filosofia do marxismo de Bogdánov, Bazárov e outros. Aqui não é o lugar oportuno para analisar este livro, e no momento, tenho que limitar-me a declarar que, não demora, irei demonstrar em uma série de artigos, ou em um folheto especial, que tudo o que se disse no texto sobre os revisionistas neokantianos guarda, também, relação, em essência com estes "novos" revisionistas neohumanistas e neoberkelianos. (Nota das Edições Avante! Veja-se V. I. Lénine, Obras, $5^{\mathrm{a}}$ ed. em russo, t. 18)

7 [Nota das Edições Avante!] Partido Democrata-Constitucionalista ("cadetes"): principal partido da burguesia monárquica liberal na Rússia, foi formado em Outubro de 1905. Faziam parte dele representantes da burguesia, dos latifundiários e dos intelectuais burgueses. Depois da vitória da Grande Revolução Socialista de Outubro os democratas-constitucionalistas mostraram-se inimigos irreconciliáveis do Poder Soviético, tomaram parte em todas as ações armadas contrarrevolucionárias e campanhas dos intervencionistas.

8 [Nota das Edições Avante!] Millerandismo (ministerialismo): corrente oportunista na social-democracia, assim designada segundo o nome do socialista-reformista francês Millerand que, em 1899, entrou no governo burguês reacionário da França e apoiou a sua política antipopular.

9 [Nota das Edições Avante!] Guesdistas: corrente revolucionária marxista no movimento socialista francês do fim do século XIX e do início do século XX, que foi dirigida por J. Guesde e P. Lafargue. Em 1882, após a cisão do Partido Operário de França no Congresso de Saint-Étienne, os guesdistas formaram um partido independente, conservando a denominação antiga. Em 1901 os partidários da luta de classe revolucionária, com J. Guesde à cabeça, uniram-se no Partido Socialista de França (cujos membros passaram a ser designados pelo nome do seu guia, ou seja, guesdistas). Em 1905, os guesdistas uniram-se com o Partido Socialista Francês reformista. Durante a guerra imperialista de 1914-1918 os dirigentes deste partido (Guesde, Sembat, etc.) traindo a causa da classe operária, passaram para as posições do social-chauvinismo. Jauressistas: partidários do socialista francês J. Jaurés, que nos anos 90 fundou, em conjunto com A. Millerand, o grupo dos "socialistas independentes" e que dirigia a ala direita, reformista, do movimento socialista francês. Encobrindo-se com a exigência da "liberdade crítica", os jauressistas reviam as principais teses do marxismo, preconizavam a colaboração de classes entre o proletariado e a burguesia. Em 1902 fundaram o Partido Socialista Francês, de tendência reformista.

10 [Nota das Edições Avante!] Se refere à Federação Social-democrata da Inglaterra, fundada em 1884. Juntamente com os reformistas (Hyndman e outros) e os anarquistas, formava parte da Federação Social-democrata da Inglaterra um grupo de social-democratas revolucionários partidários do marxismo (Harry Quelch, Tom Mann, Edward Eveling, Leonora Marx e outros), que constituíram a ala esquerda do movimento socialista da Inglaterra. F. Engels criticou energicamente a Federação Social-democrata da Inglaterra pelo seu dogmatismo e sectarismo, por separar-se do movimento operário de massas da Inglaterra e por ignorar as suas peculiaridades. Em 1907, a Federação Social-democrata da Inglaterra passou a chamar-se Partido Social-democrata. Este, junto com os elementos de esquerda do Partido Operário Independente, formaram, em 1911, o Partido Socialista Britânico; em 1920, a maioria de seus filiados tomou parte na fundação do Partido Comunista da Grã-Bretanha.

Independent Labour Party (I.L.P.) (Partido Trabalhista Independente) foi fundado em 1893. Era encabeçado por James Keir Hardie, Ramsay MacDonald e outros. Ainda que pretendesse manter independência política em relação a outros partidos burgueses, na realidade, o Partido Trabalhista Independente só era "independente" do socialismo, porém "muito dependente do liberalismo" (Lênin). No começo da primeira guerra mundial (1914-1918), o Partido Trabalhista Independente publicou um manifesto contra a guerra (em 13 de agosto de 1914). Em seguida, em fevereiro de 1915, na Conferência de Londres dos socialistas dos países do Pacto, os independentes aderiram à resolução social chauvinista adotada pela Conferência. A partir de então, os líderes dos independentes, encobrindo-se com frases pacifistas, mantiveram uma posição social chauvinista. Em 1919, os líderes do Partido Trabalhista Independente, sobre pressão das massas radicalizadas do partido, acordaram em

Germinal: Marxismo e Educação em Debate, Salvador, v. 12, n. 2, p. 414421, out. 2020. ISSN: 2175-5604 420 
abandonar a II Internacional. Em 1921, os independentes ingressaram na chamada Internacional II e meio e, depois após a desagregação da mesma, voltaram a ingressar na II Internacional. Em 1921, a ala esquerda do Partido Trabalhista Independente da Inglaterra se separou do mesmo e ingressou no Partido Comunista da Grã-Bretanha.

11 [Nota das Edições Avante!] Partido Trabalhista Independente da Inglaterra (Independet Labour Party): organização reformista, fundada pelos dirigentes das "novas trade-unions" em 1893, durante a ativação da luta grevista e o fortalecimento do movimento pela independência da classe operária de Inglaterra em relação aos partidos burgueses. Aderiram ao Partido Trabalhista Independente membros de "novas trade-unions" e de uma série de velhos sindicatos, e representantes da intelectualidade e da pequena burguesia, que estavam sobre a influência dos fabianos. À frente do partido estava Keir Hardie. O Partido apresentou como seu programa a luta pela posse coletiva de todos os meios de produção, distribuição e troca, pela jornada de trabalho de 8 horas e proibição do trabalho infantil, pela introdução do seguro social e dos subsídios aos desempregados. Caracterizando o Partido Trabalhista Independente, Lénine escrevia que "na realidade era um partido oportunista sempre dependente da burguesia", que era "independente só do socialismo, mas muito dependente do liberalismo." (ver V. I. Lénine, Sobre as tarefas da III Internacional e debates ingleses sobre a política operária liberal, Obras completas, $5^{a}$ ed. em russo, t.39, p.90; t.22, p.122)

12 [Nota das Edições Avante!] No seio do Partido Operário Belga, Brouckère e os seus partidários pronunciavam-se contra a participação dos socialistas no governo burguês reacionário e conduziam a luta contra Vandervelde, que dirigia os revisionistas belgas. Posteriormente, Brouckère passou às posições oportunistas.

13 [Nota das Edições Avante!] Integralistas: partidários do socialismo "integral", uma variedade do socialismo pequeno-burguês. O dirigente dos integralistas foi Enrico Ferri. Representando a corrente centrista no Partido Socialista Italiano, os integralistas, na primeira década do século XX, combatiam numa série de questões os reformistas, que ocupavam posições extremamente oportunistas e colaboravam com a burguesia reacionária.

14 [Nota das Edições Avante!] Sindicalismo revolucionário: corrente pequeno-burguesa semianarquista, que surgiu no movimento operário duma série de países da Europa Ocidental no fim do século XIX. Os sindicalistas negavam a necessidade da luta política da classe operária, o papel dirigente do partido e a ditadura do proletariado. Pensavam que os sindicatos, pela via da organização de uma greve geral operária sem revolução, podiam derrubar o capitalismo e tomar em suas mãos a direção da produção. 